\title{
Entre a interrupção e a criação de práticas pedagógicas: a tarefa filosófica do pedagogo na escola para educação a distância
}

\section{Between interruption and creation of educational practices: the teacher's philosophical task at the school to Distance Education}

\author{
Lúcia Schneider Hardt* \\ Rosana Silva de Moura*
}

\begin{abstract}
RESUMO
Nosso propósito neste texto é apresentar alguns aspectos de uma experiência desenvolvida em educação na modalidade $\mathrm{EaD}$, tendo em vista a figura do coordenador pedagógico. A partir de uma perspectiva filosófica, procuramos incidir nossa análise para além do aspecto formal do relato de experiência, buscando significação para as práticas pedagógicas através da incorporação de elementos que elaboram a dialética entre a interrupção e a criação, presentes nessas práticas. Com o aporte filosófico de Jorge Larrosa, em diálogo com a tradição, adentramos mais fundo na própria ideia de experiência formativa. Nosso intento é o de conferir à experiência sentidos de incompletude, de desvio, de incerteza, como sendo elementos aparentemente débeis de formação, mas que ampliam a significação do humano e de sua atuação na educação. Diante dessa possível radicalidade que nos dá a filosofia, como pensar a tarefa do pedagogo na escola?
\end{abstract}

Palavras-chave: Tarefa do pedagogo. Interrupção. Criação.

DOI: $10.1590 / 0104-4060.49151$

* Universidade Federal de Santa Catarina. Centro de Ciências da Educação. Campus Reitor João David Ferreira Lima, s/n - Trindade, Florianópolis - SC. CEP: 88040-900. E-mails: rosanasilvademoura@gmail.com; luciashardt@gmail.com 


\begin{abstract}
Our purpose in this paper is to present some aspects of an experience developed in education in Distance Education mode, having the pedagogical coordinator's figure as focus. Based on a philosophical perspective, we tried to focus our analysis beyond the formal aspect of the experience narrative, seeking significance for pedagogical practices by incorporating elements that elaborate on the dialectic between interruption and creation in these practices. With the philosophical contribution of Jorge Larrosa, in dialogue with tradition, we tried to go deeper into the very idea of formative experience. Our intent is to give the experience the sense of incompleteness, deviation, uncertainty, as elements of formation which are apparently weak, but at the same time enlarge the significance of the human being and their activities in education. Given this possible radicalism that philosophy brings to us, how should we think about the coordinator's task in school?
\end{abstract}

Keywords: Coordinator's task. Interruption. Creation.

\title{
Introdução
}

A dimensão trágica da educação está por toda parte. Compreende a complexidade da vida, reconhece o sofrimento oriundo de dificuldades humanas no trato com as coisas finitas, com as turbulências no percurso da vida, com o inaudito e seu assombro. A dimensão trágica quer nos revelar que a vida se mostra em abundância e busca energia para ser vivida afirmativamente e não silenciada pelos ajustes e convenções sociais que norteiam a escola. Sim, a dimensão trágica está por toda a parte, inclusive na escola, este espaço com o qual temos no Brasil uma relação apagada de sentidos, esquecida de valor, em outras palavras, trágica.

Cumpre ainda destacar, a título introdutório, que nossa referência ao termo escola, incorporando a totalidade de seus modos de ser (vale lembrar, a multiplicidade de suas experiências mesmas), trata de uma especificidade do termo dado no formato conhecido como modalidade de Educação a Distância (EaD). Este é nosso recorte de momento.

Logo, em um curso de formação de coordenadores pedagógicos na modalidade $\mathrm{EaD}$ no estado de Santa Catarina ${ }^{1}$, a complexidade relacionada à dimensão

1 Em termos informativos, cumpre ainda referir que o curso em questão, a formação do coordenador pedagógico para as escolas públicas, é fomentado pelo Programa Escola de Gestores/ Ministério da Educação (MEC) em parceria com a Universidade Federal de Santa Catarina (UFSC/ 
trágica da escola também aparece. A grande parcela do público deste curso é de estudantes que moram distantes dos grandes centros de educação. São, em geral, professores que pela primeira vez têm contato com uma universidade pública. A maioria deles foram estudantes de cursos de graduação realizados em escolas privadas, particularmente, entre outros aspectos, porque as universidades federais brasileiras estão concentradas nos grandes centros urbanos do País, razão pela qual, em termos objetivos, o acesso a uma atualização (formação continuada) se torna mais fácil à distância. Além disso, como sabemos, o ingresso na escola de ensino superior na modalidade presencial é bastante limitado, por razões que não vamos discutir aqui em vista de nossa delimitação do tema. A caracterização inicial do público do referido curso (Coordenação pedagógica) se torna importante para que tenhamos noção do valor de uma incursão filosófica no interior dele mesmo. Para muitos estudantes e futuros coordenadores pedagógicos, a experiência reflexiva do e com o conceito, elemento primordial na reflexão filosófica atualizada mediante mudanças paradigmáticas no campo da filosofia, é o elemento de transvaloração dos conhecimentos e das verdades que foram adquiridos ao longo de suas vidas. Como não poderia deixar de ser, até o início das discussões no interior do Curso, o que está assentado como conhecimento e verdade tende a se manter em repouso - e petrificado seja pelo mero uso repetido deles mesmos (os conceitos), seja pelo desuso de uma analítica em suas práticas pedagógicas. Tomamos como questão filosófica o ponto de ser do humano expor-se ao seu contrário, ser provocado e afetado por algo para, então, ser convocado a pensar sobre este algo, daí o valor de um curso de atualização profissional de conhecimentos e verdades. Esse é o matiz filosófico de alcance maior na educação, o qual, muitas vezes esquecido, se poderia alçar voo mais alto para pensar a função do educador.

Nesse sentido, tendo como basilar a reflexão filosófica, desde qualquer ponto de um currículo, em qualquer disciplina, poder-se-ia refletir sobre sua função. Logo, não se trata aqui de destacar um lugar especial para a filosofia na educação, mas sim de espraia-la por toda a educação como sendo o seu pressuposto elementar, a saber: levar aqueles que estão imersos na escola a pensarem analiticamente seus lugares para, então, elaborarem a crítica, disso adviria o que depreendemos na academia por análise crítica; pois a crítica que não vem antecedida de uma análise se encontra aprisionada em si mesma e serve apenas

SED/UNDIME). Tem como expressão, uma política pública comprometida com a educação que visa qualificar a escola pública, observando em especial o Índice de Desenvolvimento da Educação (IDEB) das escolas envolvidas. O curso tem a duração de um ano e meio, sendo que, nos últimos cinco meses dele, cada estudante deve produzir um artigo como trabalho de conclusão, inspirado por um projeto de intervenção (PI) praticado e vivenciado na escola. 
a si mesma. Considerando que a tarefa da educação é formar o humano para ser ele aquele que forma o mundo (HEIDEGGER, 2003), nos parece tácito que formar o mundo tenha a ver com a questão indissociável de pensá-lo. Não há, segundo nossa perspectiva, formar um mundo sem querer pensá-lo. Pensar o mundo é pensá-lo filosoficamente, ou seja, pensá-lo desde um esforço teórico de abstração do imediato, mediando os elementos que formam a complexidade, que somente a disposição para o pensar pode trazer àquele que é convidado a fazê-lo enquanto mundo pensado e pensante. Assim sendo, a disposição para pensar, movimento primeiro para o exercício da reflexão, pede, imediatamente, seu complemento; a saber, as condições postas para o pensar radical e que se encontram em uma trajetória intelectual adensada no diálogo com a teoria.

Qual seria a importância da teoria nesse processo? Nas palavras de Hans-Geörg Gadamer (2001), a teoria enseja a própria destinação do humano sendo esta a possibilidade do pensar. A teoria é um esforço próprio para esmerar o pensar. Nessa perspectiva, Gadamer se encontra amparado numa tradição, originariamente articulada desde os gregos antigos, cuja culminância está localizada em Heidegger. Então, no que concerne ao termo teoria/theorein, a pergunta gadameriana tem feito, a nosso ver, todo o sentido quando pretendemos imprimir certa função ao educador.

Será a teoria, no fim de contas, uma práxis, como já Aristóteles sublinhara, ou será a práxis, se verdadeiramente humana, também e sempre teoria? Não será ela, quando é humana, um tirar os olhos de si mesmo e olhar outrem, um abstrair de si para escutar outrem? [...] Abstrair de si, atentar no que existe [...]. (GADAMER, 2001, p. 40).

Trata-se de um abstrair de si (tomado enquanto condição imediata que infere o pertencimento a um círculo vitiosum) para escuta de outrem, daquele que pode indicar uma saída no inusitado ainda não posto no imediato. Esse tem sido o exercício mais radical do lugar ao qual pertence o educador: puxar a si mesmo do lugar comum e imediato do fenômeno para dizer de algo que está um pouco mais além e ainda não visto. Logo, a experiência do pensar, à luz do espelho teorético posto para a formação e atualização de professores coordenadores pedagógicos (especificamente o caso tratado aqui), pode ser referida desde um lugar que diz de um estar disposto ao distanciamento; porque, em certa medida, os coordenadores estiveram dispostos a saírem de seus lugares imediatos. 
A partir dessas considerações filosóficas iniciais, adentramos no ponto que é o curso de formação de coordenadores pedagógicos ${ }^{2}$, professores também e responsáveis pelas dinâmicas pedagógicas mais importantes da escola. Especificamente, tomamos como base a importância da leitura naquele curso de especialização profissional. Sabemos que a vida de um coordenador não é simples, está tocada pela interrupção, pela incoerência e pela surpresa. Quando imagina ter encaminhado um problema, ele aparece de outra forma, surpreende-se e, por vezes, tomba diante da realidade. Nesse contexto voltamos a pensar: qual o lugar da filosofia nas instituições encarregadas de pensar a formação humana? Como reagir mediante uma instantaneidade constante? De alguma forma também não toleramos mais o que dura para sempre.

Segundo Bauman (1999), vivemos essa ambiguidade entre a solidez e a liquidez. Cada um desses polos absolutizados nos coloca diante do caos. A resistência constante à mudança é prejudicial; contudo, a ausência da preservação de algo também é perniciosa. Entendemos que estamos diante de dois grandes temas: segurança e liberdade nos fazendo pensar a formação humana, temas concernentes à coordenação pedagógica.

Assim sendo,

[...] os movimentos de resistência e liberdade implicaram sempre fazer derreter mundos sólidos, livrar-se de entulhos das velhas ordens. O que seria recomendável que durasse? Como lidar com as práticas educativas, considerando a velocidade e a aceleração com que os princípios ficam estabelecidos e, por vezes, interessadamente definidos? Hoje, as principais técnicas de resistência parecem ser a fuga, a astúcia, o desvio, a evitação. Os sujeitos se defendem por essas trilhas e quem está na condição da mediação tem dificuldades em estabelecer um itinerário de trabalho e enfrentamento de crises. Nossa luta parece ser uma luta, como diz Bauman (1999), contra a arte da fuga. Para que tudo possa fluir, o mundo deve estar livre de cercas, barreiras, fronteiras e barricadas. Mas o mundo pedagógico necessita de indicadores, não podemos derrubar todas as cercas. Afinal, o que deve ser preservado e o que o deve ser tocado para mudar? Qual a função do curso diante desse cenário? Formar neste contexto significa agir e pensar e nesse aspecto escrever é um exercício necessário sobre as ações que foram concretizadas na escola. Concretizar esse processo não é ocupar-se com algo simplesmente, moralizar o campo de ação, mas fazer emergir sentidos para o "estar aí" sem obrigar-se a resultados

2 Tomamos como referência algumas análises já apontadas em outro artigo intitulado "A busca da fecundidade por meio da escrita: uma tarefa para coordenadores pedagógicos da educação básica". (HARDT; ARRIAS, 2014). 
simplesmente. Não podemos esgotar as energias no mundo das vivências, mas cavar espaços para refletir sobre o mundo da existência humana. A familiaridade no contexto pedagógico implica o fazer pedagógico que sempre é menor que o agir pedagógico. Enquanto nos compreendemos, temos mais uma vez a chance de repor a pergunta pelo sentido do ser. Ser professor, ser coordenador pedagógico. A angústia produz em nós disposição de abertura e cria possibilidades para o cuidado, considera a condição de incompletude do ser humano, desafia a cada profissional fazer algo e que possa ser significativo. (HARDT; ARRIAS, 2014, p. 359).

Os coordenadores aproximam-se de um "jeito trágico-estético de ser", tão bem referido por SILVA (2011). Parecem saturados das palavras comuns, das categorias científicas da Pedagogia e dos modelos usuais e consoladores da prática. Tem nas mãos e no espírito o terrível e problemático da educação, o sólido e o líquido ao mesmo tempo. Desejam produzir a invenção, aquela que não rejeita a tradição, mas talvez possa de fato escavar o terreno para aquilo que acabou sendo dispensado exatamente por ser dito como tradicional. Voltar a pensar sobre o conceito de arete, que não é do tamanho de uma receita pedagógica, mas implica a coragem de um sujeito que reconhece de novo sua "vulcanidade" (SILVA, 2011, p. 115) instintiva para criar. A mais elevada arete é aquela que é capaz de "fazer sua a beleza". (JAEGER, 2001, p. 35). Para os gregos, aspirar a beleza significa não desperdiçar energia, mas concentrá-la no que de melhor poderá surgir de nós mesmos. Essa determinação ao que parece não é muito comum, apresenta-se de uma forma rara e singular. $\mathrm{O}$ espírito de guerra, a destreza do uso das ferramentas e das armas, exige perseverança e coragem. Infelizmente nossas guerras estão sendo delineadas unicamente pelas demandas coletivas que ficam legitimadas, pois representam a maioria. A maioria não é condição suficiente para produzir beleza, existe algo de singular na beleza e que não pode ficar minimizada em função de sua pouca liquidez quantitativa.

Precisamos deixar fluir tal sentido de vulcanidade dos coordenadores capazes de criar sua beleza, e por outro lado deixar aparecer beleza nas aulas de matemática, português, história ou arte. Cada professor tem um estilo, expressão da singularidade para forçar na escola a entrada da arte por meio de outro ritmo, outra música, outras palavras, outras práticas. Por vezes, lembrar de práticas e palavras, ritmos viçosos, originais e rejeitados pela compulsão exagerada e reguladora das maiorias. A beleza da tradição ficou substituída pelo pragmatismo da organização e pelo amaciamento das relações. $\mathrm{O}$ amoroso converteu-se em compaixão. $\mathrm{O}$ altruísmo converteu-se em "pedagogias de facilitação e práticas pedagógicas complacentes e compensatórias" (SILVA, 2011, p. 119). Desta pedagogia nasce outra - a do ressentimento: 
Esta, com um ímpeto reativo tão contundente, não dialoga com outras pedagogias, mesmo porque o seu rancor reativo só vê conspiração onde, eventualmente, pode ter existido alguma originalidade, alguma positividade ativa. E o pior é que sua radical desconfiança, que é nutrida por uma profunda (in)consciência de suas limitações e equívocos, torna-se um escudo que blinda o educador ressentido e o impede de compreender ou perceber a inversão de valores que efetivou e o forte caráter reacionário de seu procedimento. (SILVA, 2011, p. 121).

Nesse cenário fica fortalecida mais a piedade do que a Pedagogia, mais a compaixão do que a peleja que o conhecimento exige de quem dele quer se aproximar. Contudo, o rigor e a exigência não estão desprovidos do afeto, pelo contrário, o afeto é o que move o convite para viver uma possível bela experiência de aprendizagem. Atiçar o estudante para enfrentar sua curiosidade, sua criatividade, é função do educador e do coordenador. Mas tem sido difícil, pois fomos por tempo demais acomodados ao comum e ao pouco. Fomos roubados de nossa própria curiosidade, saquearam nossa possibilidade de viver uma escola de fato.

O contato com coordenadores tem nos mostrado isto. Não fomos todos ainda consumidos pela subserviência e ainda pelejamos por aí. Talvez a luta possa ainda apropriar-se mais de uma dimensão estética. Enfrentar a cultura da facilitação, que como nos tempos de Nietzsche parece ser também uma cultura decadente, exige um excesso de força, uma plasticidade teórico-prática capaz de manobrar com os preceitos supostamente inquestionáveis.

Não devemos nos prender a uma pedagogia, não batizar nossa prática com nomes revestidos de tendências pedagógicas, preservar-se do terreno antiartístico, decadente, que nos quer ver recitador de cantos alheios, fazendo prescrições pedagógicas a partir de palavras ditas adequadas, mais claras, mais justas e lógicas. Não cabe ao coordenador impedir a interrupção; contudo, não basta apenas contemplá-la. Considerando o aluno que vem à escola para aprender, o coordenador deve empreender esforços nessa direção.

Conforme nos ensina Bachelard, no seu livro A poética do espaço, é preciso proteger os "cantos do mundo" (1988, p. 24), onde possamos nos abrigar. Todo espaço realmente habitado traz a essência da casa, da proteção. A escola também deve ser protegida. Larrosa ${ }^{3}$ (2014) defende com veemência a necessidade de pensar outra vez a função do "muro da escola" em sua perspectiva metafórica. Afinal a escola é um espaço com tarefas muito específicas e não deve assumir

3 Palestra proferida em julho de 2015, na UFSC. 
tudo que uma pretensa sociedade diz que ela deve fazer. Cabe à escola também se diferenciar do mercado, de uma determinada visão de sociedade, de certas práticas de consumo e de formas de existência. Como diz Bachelard (1988, p. 26): “O devaneio tem mesmo um privilégio de autovalorização. Ele usufrui diretamente de seu ser. Então, os lugares onde se viveu o devaneio reconstituem-se por si mesmos num novo devaneio".

A escola é um lugar para imaginar, sonhar, criar, aprender e não assumir tarefas indicadas pela sociedade como prioritárias. Os profissionais da educação precisam pensar sobre a especificidade da escola, ela não fica melhor quando se iguala àquilo que a circunda. A diferenciação que ela pode fazer nascer pode ser um sinal de mudança social. O espaço escola convida à ação, e antes disso, nos termos de Bachelard, está a imaginação que trabalha. $\mathrm{O}$ benefício da imaginação é colocar-se diante do mundo de uma forma singular. Preservar o tempo para essa tarefa, sem pressa, afinal a "casa primordial deve guardar sua penumbra" (BACHELARD, 1988, p. 32), pois no devaneio das crianças existe o privilégio da profundidade. Afinal, feliz é

a criança que possuiu, que realmente possuiu as suas solidões! É bom, é saudável que uma criança tenha suas horas de tédio, que conheça a dialética do brinquedo exagerado e dos tédios sem causa, do tédio puro. (1988, p. 35).

Aqueles que "esperam" a criança, não suportam o tédio, a penumbra, o devaneio, a paciência das aprendizagens e com pressa querem indicar o que devem fazer para ajustarem-se às necessidades do mercado e de um modelo de sociedade. Interrupção, como ação pedagógica para resistir aos excessos do ajustamento, excessos da igualdade que nos encaixam todos em um único ritmo. Será preciso exercitar a arte da fuga, como nos ensina Bauman (1999). Dessa arte vem a surpresa de uma outra possibilidade de inserção no mundo. Nesse aspecto o trágico converte-se em uma possibilidade estética. Não está em questão banalizar o espaço escola, ele é por excelência um lugar de formação e de boa formação. Nesse contexto preservar suas particularidades é fundamental.

A vida exige acréscimo de energia, expansão, alargamento, extensão. Impedir esta pulsão significa impedir o mais refinado estado de formação humana. Nesse cenário a pressa, a simplificação, a banalização não tem lugar. $\mathrm{O}$ ato criativo é escasso porque somos excessivamente adequados, ajustados a nosso tempo. Nosso ajustamento é incompatível com a força e as manobras de quem supera seu tempo para criar. No cenário de expansão, existe lugar para 
uma escola capaz de fazer acontecer com plasticidade formas pedagógicas que promovam o pensar.

Para Nietzsche (2011), a educação precisa jogar com duas grandes forças: asas e freios. Coordenadores pedagógicos precisam pensar a formação de professores nessa direção. Como garantir que exista espaço para a curiosidade dos alunos e como frear o que ainda é precário em sua prática. Significa afirmar práticas, lentificar o tempo como nos aponta Larrosa (2014), educação solicita a plenitude da atenção, não estamos na escola para atender apenas aos interesses dos alunos, mas também solicitar a atenção deles para aquilo que já não sabem mais dar valor: como estudar, o que fazer com as palavras. Por vezes a escola tem a tarefa de distanciar o aluno de seus interesses. Estar presente na escola para que algo aconteça. Não repetir o que já acontece fora da escola. Escola é também diferenciação, separação, muro, porta para formar a atenção do estudante. A escola deve separar as crianças do que é imediato para fazê-las ver outro mundo com menos pressa. Concentrar-se mais tempo na mesma coisa, repetir é necessário. O coordenador pedagógico trata diariamente com uma miríade de questões do humano. O mundo lhe chega cotidianamente e o impele à leitura. O mundo é um texto a ser lido, precisamos da razão e de nossa sensibilidade. Entrar em contato com as palavras para escolhê-las, dispensar outras, criar novos arranjos. Ter curiosidade com as palavras implica estudar. Mas não só o mundo relacional lhe chega - também o mundo das palavras e dos textos escritos lhe assaltam a dimensão do desejo. Ler, escrever, copiar são tarefas de sua lida diária e que foram intensificadas na atualização profissional, tal como aconteceu no Curso do qual trazemos à mostra.

A cada um dos coordenadores instalou-se o instante do revigorar de seu métier por meio de leitura e escrita, tendo por suporte as TICs ${ }^{4}$. Experiências de leitura e de escrita nas modulações e variações de tempo. Descompassos, velocidades e letargias. Interrupções de leitura, desvios de escrita, insondáveis abstrações. Curiosas inquietações. E o escrever? Escrever é lentificar o tempo. E, mesmo assim, escrever é quebrar o sentido originário e provisório de algo. Escrever é lembrar e esquecer. E, mesmo assim, precisamos escrever, pois falamos muito apressadamente. É próprio da escrita, por vezes, pedir um tempo mais demorado. Efetivamente, cuidamos mais do que escrevemos do que dizemos. Parece, então, que precisaríamos cultivar ecologias da atenção. Estamos seduzidos pela dispersão e pela pressa. Antes de qualquer opinião, muitas horas de leitura, texto tem autoridade. Fazer muita crítica antes da leitura é profanação do texto. Pois, o que pede o texto? Em primeira mão, o mais elementar: sua leitura (exercício originário de toda a crítica na academia), pois sua leitura é

4 Tecnologias de Informação e Comunicação. 
o reconhecimento de seu lugar. Assim sendo, o texto, para dizer-se, solicita a presença do leitor que o traz à tona. Texto sem leitor é como palavra guardada e sem uso, sem luz. Vindo à luz, toma corpo e se faz presença, não necessariamente como verdade, mas como presença que interrompe o imediato, pausa e pode fazer pensar. Na leitura de um texto, sempre há o instante que nos faz pensar, por identificação ou diferença, o que fazemos. Por isso, o exercício de cópia de um texto, segundo Larrosa (2014), nos faz pausar e inventar um tempo outro de leitura no qual nosso corpo se implica na leitura e na relação com as palavras dele mesmo, o texto. Suspendemos nossa imediatez no mundo para então nos deixarmos navegar naquele mar de palavras e sentidos que nos puxam para dentro de si e, com isso, reinventamos nosso próprio lugar no ato de uma abstração de nós mesmos para deixar ver aquela viagem na qual estamos adentrando: a viagem do texto. "Abstrair de si, atentar no que existe": soam mais uma vez as palavras de Gadamer (2001, p. 40), doando sentidos na transvaloração do imediato ao mediado. E o que ali existe é o texto e seu mundo, o qual ele mesmo nos apresenta. Outro mundo, outra letra, outro sentido, outra existência. O texto é um outro. Nessa perspectiva, a cópia literal e física do texto é um exercício formativo: precisamos vê-lo mais uma vez, escrever de novo, refazer leituras. Nesse sentido, o corpo leitor que labuta aquelas palavras - as palavras outras, presentifica-se na relação com o texto, debruçando-se e desdobrando-se na experiência da leitura, da cópia, da interpretação. Temos aí um tanto de experiência formativa e o exercício da cópia torna-se educativa e não punitiva. Ela passa a ser então, um modo pelo qual estabelecemos a intimidade com as palavras do texto. Dói que a leitura tenha se tornado a falta de um tempo mais demorado no texto para tornar-se apenas uma ação obrigatória, uma busca desesperada e ligeira por uma ideia central a ser escavada nele, como um procedimento repetido por uma racionalidade mecânica no interior da educação. Há um predomínio exagerado da rapidez e da eficácia na transmissão e, por isso, cada vez mais, algumas formas de expressão poética e artística são mais escassas. A linguagem viva - essa linguagem que não se deixa fisgar por informações e opiniões, por urgências e brevidades - é a linguagem da travessia, que produz vivências.

Procuramos mostrar nuanças de experiência de trato com o texto enquanto experiência humana que traz consigo sentidos de incompletude, de desvio, de incerteza. Poder-se-ia atribuir a esses sentidos de formação, aparentemente frágeis, motivos de interrupção do fazer pedagógico. Todavia, a filosofia tem oferecido contribuições que ampliam a significação do humano para deixar ver com sua radicalidade que a escola (presencial ou a distância) é uma parte do mundo em abertura. Mundo frágil, incompleto, incerto, armado em desvios, a construir de suas faltas também as nossas curiosas vontades de fazer e refazer 
suas linhas e sentidos. Sob essa inspiração, a lida com o texto na escola ainda nos parece uma experiência fértil para a formação. Nosso intento nesse texto, conforme anunciamos no início, foi o de conferir à experiência da leitura o lugar merecido na formação escolar, seja na modalidade presencial seja na modalidade a distância.

\section{REFERÊNCIAS}

ARRIAS, N.; HARDT, L. A busca da fecundidade do pensamento por meio da escrita:14HARDT, L. S.2014 uma tarefa para coordenadores pedagógicos da educação Básica. Contrapontos (Online), v. 14, p. 353-366, 2014. Disponível em: <http://dx.doi. org/10.14210/contrapontos.v14n2.p353-366>.

BACHELARD, G. A poética do espaço. São Paulo: Martins Fontes, 1988.

BAUMANN, Zygmunt. Modernidade e ambivalência. Trad. Marcus Penchel. Rio de Janeiro: Jorge Zahar Ed. 1999.

HEIDEGGER, M. Os conceitos fundamentais da metafísica: mundo, finitude e solidão. Rio de Janeiro: Forense Universitária, 2003.

GADAMER, H-G. Elogio da teoria. Tradução: João Tiago Proença. Lisboa: Edições 70, 2001

JAEGER, W. Paidéia. A formação do homem grego. Tradução: Artur M. Parreira. São Paulo: Martins Fontes, 2001.

LARROSA, J. Tremores-escritos sobre a experiência. Belo Horizonte: Autêntica editora, 2014.

NIETZSCHE, F. Para além do bem e do mal: prelúdio a uma filosofia do futuro. Tradução, notas e posfácio: Paulo César de Souza. São Paulo: Companhia das Letras, 1992.

NIETZSCHE, F. Humano demasiado humano: um livro para espíritos livres. Tradução, notas e posfácio: Paulo César Souza. São Paulo: Companhia das Letras, 2005.

NIETZSCHE, F. Crepúsculo dos ídolos ou como se filosofa com o martelo. Tradução: Paulo César de Souza. São Paulo: Companhia das Letras, 2006.

NIETZSCHE, F. O nascimento da tragédia. Tradução, notas e posfácio: J. Guinsburg. São Paulo: Companhia das Letras, 2007.

NIETZSCHE, F. Assim falava Zaratustra: um livro para todos e para ninguém. Tradução: Mário Ferreira dos Santos. Petrópolis: Vozes, 2007. 
NIETZSCHE, F. W. Sobre o futuro dos nossos estabelecimentos de ensino. In: Escritos sobre educação. Tradução Noéli Correia de Melo Sobrinho. 5. ed. Rio de Janeiro: PUC-Rio. São Paulo: Loyola, 2011. 352 p.

SILVA, S. Pedagogia do ressentimento: o otimismo nas concepções e nas práticas de ensino. Revista Brasileira de Estudos Pedagógicos, Brasília, v. 92, n. 230, p. 107-125, jan./abr. 2011.

Texto recebido em 03 de novembro de 2016.

Texto aprovado em 13 de abril de 2017. 